\section{Corneal topography in patients with congenital ptosis}

\begin{abstract}
Purpose To determine the effect of congenital ptosis on corneal shape, and to assess the role of these topographic changes in the development of amblyopia.

Methods Twenty-two patients with congenital ptosis were examined and a corneal topographic examination performed in both the ptotic and normal eyes. The qualitative corneal classification was done according to the colour-coded topographic maps. The surface regularity index (SRI) and the surface asymmetry index (SAI) were used as quantitative descriptors of the study. Results Ptotic eyes had an increased incidence of astigmatism, bow tie pattern on corneal topography, corneal asymmetry (SAI, $p<0.05$ ) and corneal irregularity (SRI, $p<0.05$ ). Lack of mirror-image symmetry with the fellow eye was higher in amblyopic eyes.

Conclusion Eyes with congenital ptosis have an increased incidence of astigmatism and a bow tie pattern on corneal topography. These features are associated with the presence of amblyopia.
\end{abstract}

Key words Amblyopia, Congenital, Corneal topography, Ptosis

\section{S.H. Uğurbaş \\ G. Zilelioğlu \\ Ankara University \\ Faculty of Medicine \\ Department of \\ Ophthalmology \\ Ankara, Turkey}

Dr Suat Hayri Uğurbaş Halk sok 21/10 Yenişehir Ankara 06420

Turkey

Tel: +90 3124351015

e-mail: shugurbas@usa.net

Received: 15 October 1998 Accepted in revised form: 11 May 1999
SUAT HAYRI UĞURBAŞ,

GÜLER ZILELIOǦLU effect of the eyelid on corneal topography and its impact on refractive errors and associated amblyopia.

\section{Patients and methods}

We analysed 44 corneas of 22 patients who had congenital ptosis. Patients with traumatic ptosis, neurofibromatosis, blepharophimosis, third and sixth nerve palsy, double elevator palsy, dry eye and atopic conjunctivitis were excluded.

Children who had poor cooperation for corneal topographic examination were also eliminated.

Routine ophthalmological examination was performed in all patients. Visual acuities were determined by Snellen chart and refractions with cycloplegia were measured. All refractions were expressed in the plus cylinder form for consistency. Amblyopia was diagnosed as a difference of 2 Snellen lines with best-corrected vision. Anisometropia was defined as a refractive difference of at least 1 dioptre of sphere or cylinder between the two eyes.

Palpebral fissure and levator functions were measured by the lid excursion method. Ptosis was classified as mild (lid droop less than or equal to $2 \mathrm{~mm}$ ), moderate (lid droop between 2 and $4 \mathrm{~mm}$ ) or severe (lid droop greater than or equal to $4 \mathrm{~mm}$ ).

Corneal topography was performed using the Topographic Modelling System-1 (TMS-1; Computed Anatomy, New York, NY) and a technician who ensured proper alignment of the patient. While the keratographs of the ptotic eye were taken, the technician, without compressing the cornea, opened the upper lid. Colour-coded map of both eyes were generated. The same investigator (S.H.U.) did all the topographic measurements.

A printout of the colour-coded map for each eye in the normalised scale was made. In this scale, all 11 available colours were used in each keratograph regardless of the range of dioptric powers across the cornea. We classified the corneas according to a qualitative classification method described previously. ${ }^{5}$ All keratographs were described on the basis of the configuration of the predominant pattern of one of the middle four of 11 colours depicted (brown, tan, gold 
and yellow). The pattern of the red zone and colours peripheral to the yellow zone were not used for classification. As a result, five types of corneal figures were defined: round, oval, symmetrical bow tie, asymmetrical bow tie and irregular. ${ }^{5}$

The simulated keratometry value (Sim K), the surface asymmetry index (SAI), and the surface regularity index (SRI) were used as quantitative descriptors of cornea. ${ }^{6}$ The Sim $\mathrm{K}$ is obtained from all power points on the seventh, eighth and ninth rings of the videokeratoscope. This position approximates the location of standard keratometry measurements. Sim K provides the power and the location of the steepest meridian and the meridian $90^{\circ}$ away.

The SAI is a measure of central corneal symmetry that monitors the central $2 \mathrm{~mm}$. It is obtained by summing the differences in corneal power of corresponding points $180^{\circ}$ apart on 128 equally spaced meridians that cross the four central videokeratoscope mires. SAI increases as the cornea becomes more asymmetrical.

The SRI is a measure of central corneal irregularity that increases as the cornea becomes more irregular. It is determined by summing local fluctuations in power along 256 equally spaced hemimeridians on the 10 central mires. The index approaches zero for a normal smooth corneal surface. The SAI and SRI values for a group of 400 normal eyes were reported to be $0.29 \pm 0.16$ (standard deviation) and $0.35 \pm 0.29$, respectively. ${ }^{7}$ In normal eyes $\mathrm{SAI}<0.5$ and $\mathrm{SRI}<1.0$.
The significance of the difference was assessed between two groups using the Wilcoxon test of the Mann-Whitney $U$-test, and for multiple groups using the Kruskal-Wallis test.

\section{Results}

Forty-four eyes of 22 patients with congenital ptosis were analysed. The ptosis was bilateral in 5 cases (23\%). Table 1 shows that those with ptosis had an increased incidence of astigmatism, bow tie pattern on corneal topography, corneal asymmetry (SAI, $p<0.05)$ and corneal irregularity (SRI, $p<0.05$ ). There was no significant difference between ptotic eyes with and without amblyopia. None of the eyes with ptosis had a round pattern on corneal topography. For the oval and bow tie patterns the steep meridian was within $20^{\circ}$ of the vertical in $6(67 \%)$ of the normal eyes and $15(60 \%)$ of the ptotic eyes. The SRI and SAI were not significantly correlated with the severity of the ptosis or the best spectacle-corrected visual acuity.

Mirror image symmetry between fellow eyes was absent in $11(65 \%)$ of the unilateral cases, and only 1 (20\%) of the bilateral cases (Figs. 1-3).

A total of 7 patients (32\%) had amblyopia, and 6 of these had unilateral ptosis. All amblyopic cases except the bilateral one had lack of mirror-image symmetry with the fellow eye. Amblyopia was associated with anisometropia in 6 cases, and strabismus in the remaining 1 . Three of the patients had myopia of $-6.50 \mathrm{D}$ or more.

Table 1. Summary of the results of the refractive and topographic examination

\begin{tabular}{|c|c|c|c|}
\hline Results for individual patients & No ptosis & $\begin{array}{l}\text { Ptosis without } \\
\text { amblyopia }\end{array}$ & $\begin{array}{l}\text { Ptosis with } \\
\text { amblyopia }\end{array}$ \\
\hline Number of patients & 17 & 20 & 7 \\
\hline Age (years; range, mean $\pm \mathrm{SD}$ ) & $4-42,15.6 \pm 9.8$ & $4-42,13.6 \pm 8.3$ & $6-32,18.8 \pm 8.9$ \\
\hline $\begin{array}{l}\text { Ptosis severity (number, \%) } \\
\text { Small }(<2 \mathrm{~mm}) \\
\text { Medium }(2-4 \mathrm{~mm}) \\
\text { Large }(>4 \mathrm{~mm})\end{array}$ & & $\begin{array}{r}7(35 \%) \\
10(50 \%) \\
3(15 \%)\end{array}$ & $\begin{array}{l}2(29 \%) \\
3(44 \%) \\
2(29 \%)\end{array}$ \\
\hline $\begin{array}{l}\text { Spherical equivalent (number, \%) } \\
\quad>+1.00 \mathrm{D} \\
<+1.00 \mathrm{D}\end{array}$ & $\begin{array}{c}1(6 \%) \\
2(12 \%)\end{array}$ & $\begin{array}{l}1(5 \%) \\
3(15 \%)\end{array}$ & $\begin{array}{l}2(29 \%) \\
4(57 \%)\end{array}$ \\
\hline $\begin{array}{l}\text { Astigmatism } \\
\text { Mean } \pm \mathrm{SD} \\
>1.00 \mathrm{DC} \text { (number, \%) }\end{array}$ & $\begin{array}{l}0.42 \pm 0.42 \\
1(6 \%)\end{array}$ & $\begin{array}{l}0.71 \pm 0.61 \\
0.71 \pm 0.61\end{array}$ & $\begin{array}{l}0.95 \pm 1.01 \\
5(72 \%)\end{array}$ \\
\hline $\begin{array}{l}\text { Anisometropia (number, \%) } \\
>1.00 \mathrm{DS} \text { or } 1.00 \mathrm{DC}\end{array}$ & $2(12 \%)$ & $2(10 \%)$ & $6(86 \%)$ \\
\hline $\begin{array}{l}\text { Topographic pattern (number, \%) } \\
\text { Round } \\
\text { Oval } \\
\text { Symmetrical bow tie } \\
\text { Asymmetrical bow tie } \\
\text { Irregular }\end{array}$ & $\begin{array}{c}4(23 \%) \\
5(29 \%) \\
4(23 \%) \\
- \\
4(23 \%)\end{array}$ & $\begin{array}{c}- \\
10(50 \%) \\
7(35 \%) \\
1(5 \%) \\
2(10 \%)\end{array}$ & $\begin{array}{c}- \\
- \\
5(71 \%) \\
2(29 \%) \\
-\end{array}$ \\
\hline Lack of mirror-image symmetry with fellow eye (number, \%) & $10(50 \%)$ & $5(25 \%)$ & $5(71.4 \%)$ \\
\hline $\begin{array}{l}\text { Surface asymmetry index (SAI) } \\
\text { Mean } \pm \text { SD } \\
>0.5 \text { (number, \%) }\end{array}$ & $\begin{array}{l}0.32 \pm 0.17 \\
3(18 \%)\end{array}$ & $\begin{array}{l}0.46 \pm 0.31 \\
\quad 7(35 \%)\end{array}$ & $\begin{array}{l}0.95 \pm 1.01 \\
2(29 \%)\end{array}$ \\
\hline $\begin{array}{l}\text { Surface regularity index (SRI) } \\
\text { Mean } \pm \text { SD } \\
>1.0 \text { (number, \%) }\end{array}$ & $\begin{array}{c}0.48 \pm 0.24 \\
-\end{array}$ & $\begin{array}{l}0.63 \pm 0.26 \\
1(5 \%)\end{array}$ & $\begin{array}{l}0.82 \pm 0.45 \\
2(29 \%)\end{array}$ \\
\hline
\end{tabular}



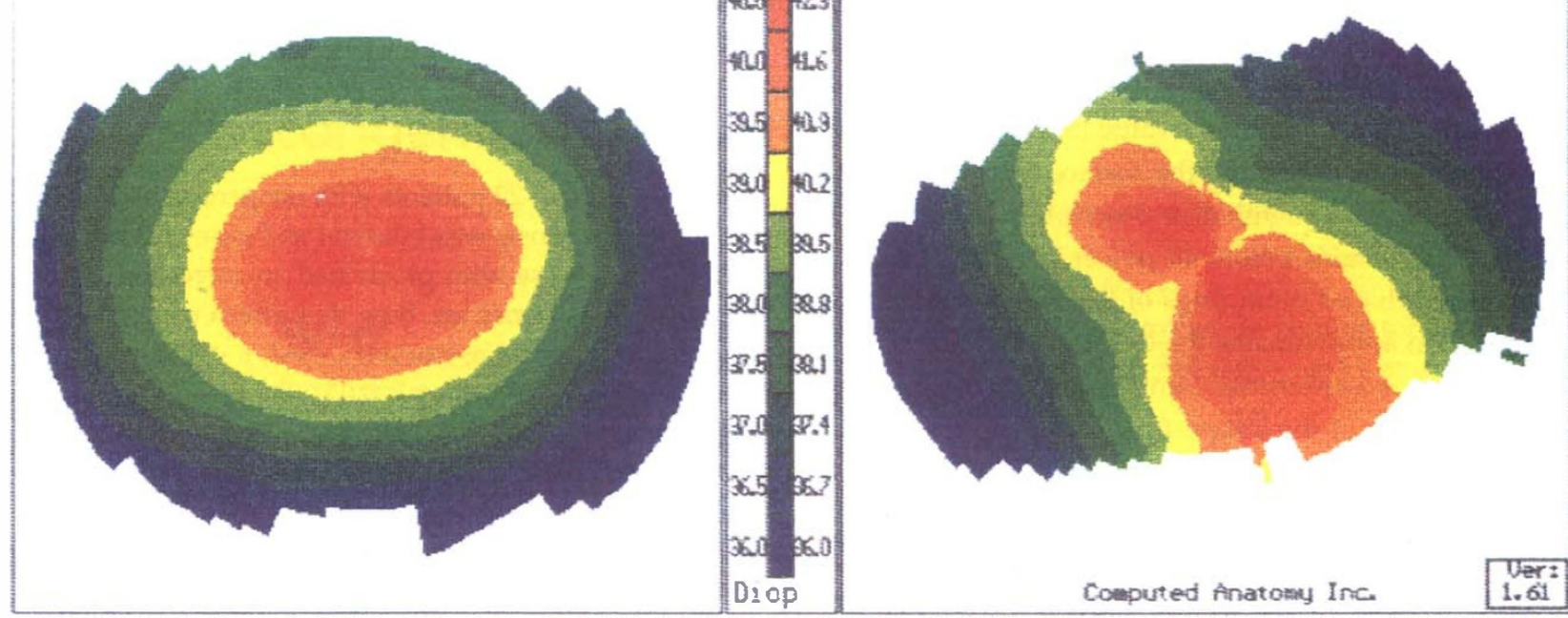

Fig. 1. Round corneal pattern in normal right eye and bow tie pattern in ptotic left eye of a patient.

\section{Discussion}

Computer-assisted corneal topography is an important device for imaging corneal contour. Robb ${ }^{4}$ demonstrated that haemangiomas appeared to be in a position from which they would exert pressure on the eye in a direction perpendicular to the axis of the negative refractive cylinder. The pressure of the haemangioma, therefore, appeared to have steepened the corneal curvature along this meridian. ${ }^{4}$ Corneal topography showed a similar pattern (symmetrical and asymmetrical bow tie) in $59 \%$ $(16 / 27)$ of our cases.

The bow tie patterns (both symmetrical and asymmetrical) had a statistically significant and clinically meaningful greater amount of astigmatism than the other patterns. ${ }^{5}$ The higher incidence of clinically significant astimatism in the ptotic eyes was in accordance with the most common corneal pattern observed in our series. We had 9 ptotic eyes (33\%) with more than $1 \mathrm{D}$ astigmatism compared with only $1(6 \%)$ in the control group.

Bogan et al. ${ }^{5}$ stated that variation in corneal topography probably forms a continuum ranging from spherical to toroidal. The corneal topography of ptotic eyes also contributes to this continuum and there is a shift towards the toroidal side since no round pattern was detected in ptotic eyes. The major corneal pattern of the ptotic eyes was the bow tie pattern.

The topography of one cornea is often the mirror image of the topography of the fellow eye. ${ }^{8}$ This high degree of mirror image symmetry often found between right and left eyes of normal individuals is similar to that in thumbprints and hands. In a significant number of

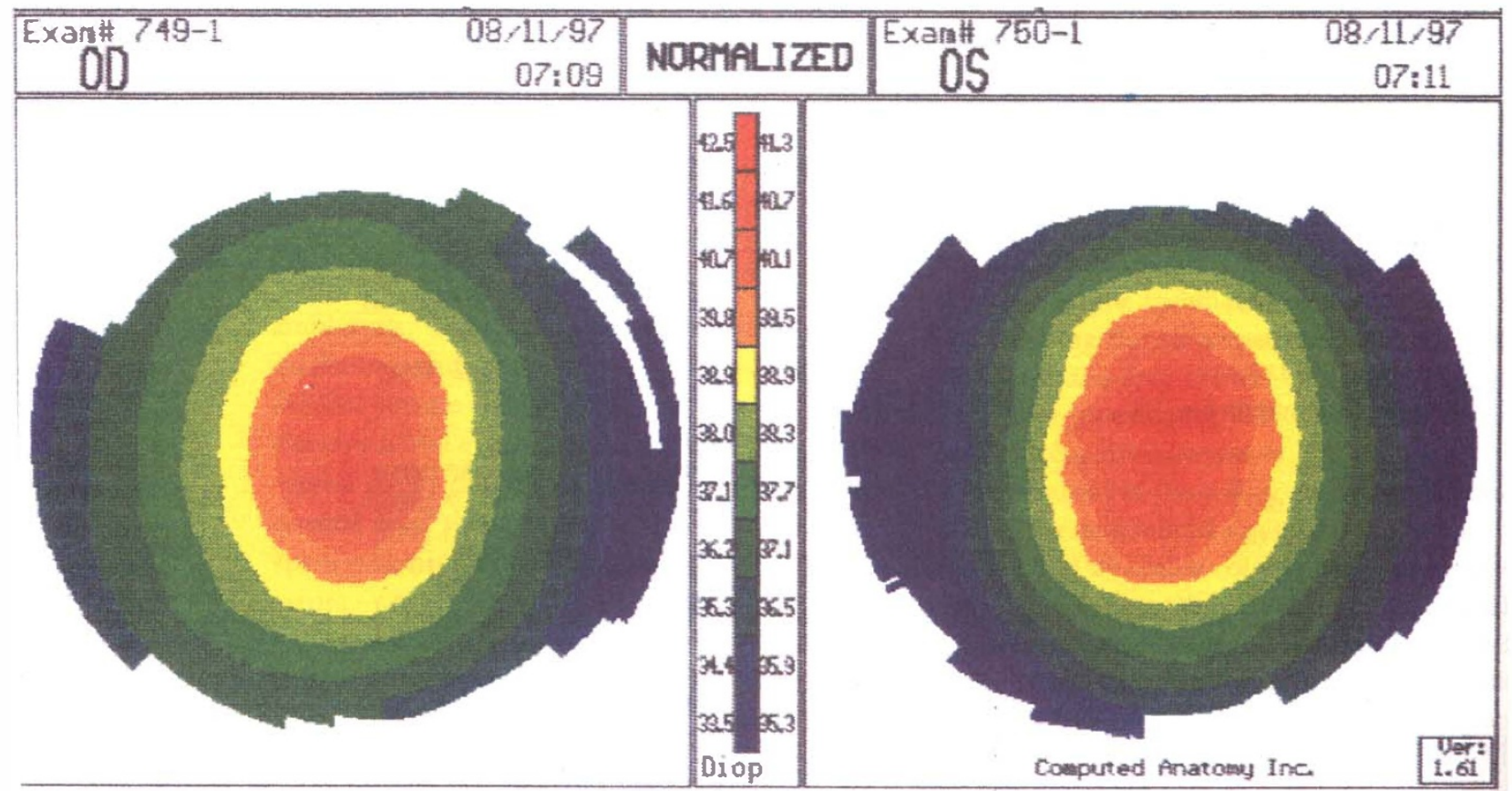

Fig. 2. Bilateral oval corneal pattern in a patient with bilateral ptosis. 


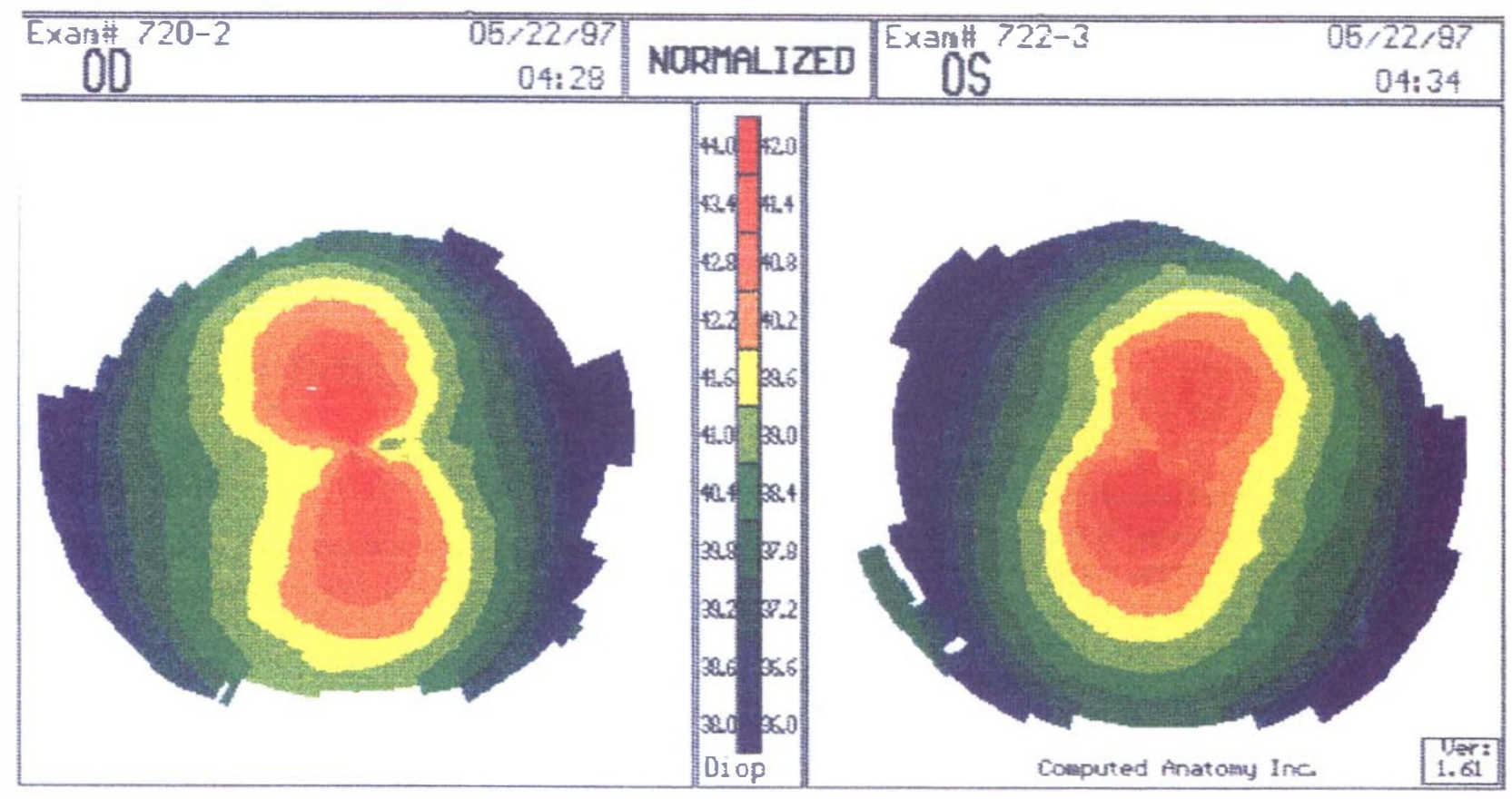

Fig. 3. Bilateral bow tie pattern in the right and left eyes of a patient with bilateral ptosis.

patients with unilateral ptosis this symmetry is reduced. The higher SRI and SAI values of ptotic eyes compared with the contralateral normal eye quantitatively demonstrate this situation. Although the two quantitative indexes showed a difference between the two eyes in all cases, qualitative classification showed different patterns in 11 cases (65\%) with unilateral ptosis. Ptosis was mild in 4 of 6 cases preserving bilateral corneal symmetry. Interestingly, lack of mirror-image symmetry was higher in ptotic eyes with amblyopia.

SRI and SAI were designed to evaluate localised surface regularity and corneal asymmetry, respectively, in the central cornea. Since the normal corneal surface has a high degree of corneal symmetry, these indexes were found to be useful for monitoring changes in corneal topography. ${ }^{9}$ Wilson and Klyce ${ }^{6}$ found a correlation between the best spectacle-corrected visual acuity (BSCVA) and both SRI and SAI. Although SRI and SAI were higher in ptotic eyes, BSCVA did not correlate with these indexes in our series. Those authors pointed out that topographic analysis was not free from the possible effects of the retinal contribution to image processing. ${ }^{6}$ They also showed that similar BSCVA values were possible over a wide range of surface regularity values. Anisometropia and strabismus were other factors that affected the visual acuity of ptotic eyes in our study. Although it was clear that the eyelid caused a deterioration in corneal regularity and symmetry, probably it was not the only factor for developing amblyopia in those patients.

The incidence of amblyopia in patients with congenital ptosis was high (32\%). This incidence ranged from $14 \%$ to $19 \%$ in previous studies. ${ }^{1,2}$ The higher incidence in our study was probably due to the higher age of presentation of our patients. Although there have been reported cases of amblyopia without an apparent cause other than ptosis, ${ }^{1,2}$ we had no such case in our series. All amblyopic eyes had a bow tie pattern and higher spherical equivalence with a higher dioptre of astigmatism.

We did not find an association between the degree of ptosis and amblyopia. This finding was in accordance with Beneish et al.'s work ${ }^{9}$ and contrary to that of Hornblass et al. ${ }^{1}$ which had indicated a correlation between severe ptosis and the development of amblyopia.

This study has shown that eyelid ptosis has a detrimental effect on corneal topography, which was more asymmetrical and irregular in ptotic eyes compared with the non-ptotic eyes. Although congenital ptosis is associated with increased corneal astigmatism, asymmetry and irregularity, this is probably not the only aetiological factor in the development of amblyopia. Other factors might include primary anisometropia and visual deprivation.

We recommend frequent refractions to ensure that best spectacle-corrected acuity is obtained. Corneal astigmatism is a major problem in ptotic eyes, and corneal topography is a useful tool to determine whether the astigmatism is regular or irregular in those patients. Hard contact lenses could be used in older children with irregular astigmatism.

\section{References}

1. Hornblass A, Kass LG, Ziffer AJ. Amblyopia in congenital ptosis. Ophthalmic Surg 1995;26:334-7.

2. Merriam WW, Ellis FD, Helveston EM. Congenital blepharoptosis, anisometropia and amblyopia. Am J Ophthalmol 1980;89:401-7.

3. Klyce SD. Computer-assisted corneal topography. Invest Ophthalmol Vis Sci 1984;25:1426-35. 
4. Robb RM. Refractive errors associated with hemangiomas of the eyelids and orbit in infancy. Am J Ophthalmol 1977;83:52.

5. Bogan SJ, Waring GO, Ibrahim O, Drews C, Curtis L.

Classification of normal corneal topography based on computer-assisted videokeratography. Arch Ophthalmol 1990;108:945-9.

6. Wilson SE, Klyce SD. Quantitative descriptors of corneal topography: a clinical study. Arch Ophthalmol 1991;109:349-53.
7. Holland DR, Maeda N, Hannush SB, et al. Unilateral keratoconus: incidence and quantitative topographic analysis. Ophthalmology 1997;104:1409-13.

8. Dingeldein SA, Klyce SD. The topography of normal corneas. Arch Ophthalmol 1989;107:512-8.

9. Beneish R, Williams F, Polomeno RC, Little JM, Ramsey B. Unilateral congenital ptosis and amblyopia. Can J Ophthalmol 1983;18:127-30. 